\title{
CARACTERIZACIÓN GEOLÓGICA Y GEOMORFOLÓGICA DEL MUNICIPIO DE JOÃO PESSOA - PB, BRASIL
}

\author{
GEOLOGICAL AND GEOMORPHOLOGICAL \\ CHARACTERIZATION OF JOÃO PESSOA \\ MUNICIPALITY - PB, BRAZIL
}

\author{
Tamires Silva Barbosa ${ }^{1}$ \\ Universidade Federal da Paraíba/Brasil. \\ Laura Marcela Torres Gomez $z^{2}$ \\ Autonoma/Colombia. \\ Max Furrier ${ }^{3}$ \\ Universidade Federal da Paraíba/Brasil
}

\section{RESUMEN}

Este trabajo tiene como objetivo la caracterización de aspectos geológicos y geomorfológicos del municipio de João Pessoa, Estado de Paraíba, a través de la elaboración de un mapa geomorfológico con metodología desarrollada en Brasil, basado en la morfoestructura y morfoescultura. La cartografía geomorfológica del municipio ofrece una amplia gama de información sobre datos litológicos, morfométricos, morfogenéticos y morfográficos. Estas informaciones son esenciales

1 Mestre em Geografia/Centro de Ciências Exatas e da Natureza/Universidade Federal da Paraíba/Brasil. E-mail: mires.ufpb@gmail.com

2 Ingeniera Geográfica y Ambiental/Autónoma/Colombia. E-mail: lautorres.ltg@gmail.com

3 Professor Adjunto, nível IV/Departamento de Geociência/Centro de Ciências Exatas e da Natureza/ Universidade Federal da Paraíba/Brasil. E-mail: max.furrier@hotmail.com 
Tamires Silva Barbosa, Laura Marcela Torres Gomez, Max Furrier. Caracterización geológica y geomorfológica del municipio de João Pessoa - PB, Brasil

para cualquier estudio socio-espacial, especialmente en relación con la ocupación en las diferentes características morfológicas que componen el municipio. Como principales resultados se obtuvieron la distinción y cuantificación de unidades geológicas y geomorfológicas presentes en el municipio y los procesos geomorfológicos actuales, que son responsables de la génesis de las formas contemporáneas del relieve.

Palabras clave: Morfometría; cartografía geomorfológica; Formación Barreiras.

\begin{abstract}
This paper aims at characterizing geological and geomorphological aspects of the township of João Pessoa, Paraíba State, through the creation of a geomorphological map with methodology developed in Brazil, based on morphostructural and morphostructural aspects. The geomorphological mapping of the town offers a wide range of information on lithological, morphometric, morphographic and morphogenetic data. This information is essential to any social space study, especially in relation to the occupation in different morphological attributes that would compose the municipality. The main results were the distinction and quantification of geological and geomorphological units present in the municipality and current geomorphological processes responsible for the genesis of contemporary forms of relief.
\end{abstract}

Keywords: Morphometrics; geomorphological mapping; Barreiras Formation.

\title{
Introducción
}

El presente trabajo tiene como objetivo presentar una caracterización de los aspectos geológicos y geomorfológicos del área correspondiente al municipio de João Pessoa, capital del Estado de Paraíba, a través del análisis cualitativo y cuantitativo del mapa geológico y la elaboración del mapa geomorfológico. Para esto, fueron elaborados productos cartográficos como el Modelo Numérico del Terreno (MNT), mapas de altimetría e inclinación de las pendientes y un mapa geomorfológico basado en la metodología de Ross (1992) con adaptaciones de Furrier (2007).

El estudio del municipio de João Pessoa se justifica por el hecho de que el mismo sufre una fuerte expansión urbana sobre los diversos compartimientos geológicos y geomorfológicos presentes y el desconocimiento de los mismos en la escala adecuada. El mapeo geomorfológico del área y el análisis del mapa geológico fueron los principales medios para que este estudio se realizara con mayor precisión. A partir de estos, se obtuvieron datos cuantitativos y cualitativos inéditos acerca de las unidades geológicas constantes, como los datos geomorfométricos, morfológicos, informaciones morfográficas y datos morfogenéticos de la geomorfología del municipio. 


\section{Área de Estudio}

El municipio de João Pessoa está localizado en el litoral del Estado de Paraíba, Brasil. Limita con los municipios de Cabedelo al norte, Conde al sur, Bayeux y Santa Rita al oeste y con el Océano Atlántico al este. Se encuentra en la Mesorregión de la Zona da Mata Paraibana, abarcando un área total según Brasil (2010) de 211,475 Km².

El espacio territorial del municipio tiene su malla urbana dispersa sobre áreas de cuencas hidrográficas, como es el ejemplo del río Gramame y los ríos de Paraíba y Sanhauá. Predomina el clima tropical húmedo con temperaturas medias anuales aproximadas a $\operatorname{los} 26^{\circ} \mathrm{C}$ y una precipitación media anual de $1.874 \mathrm{~mm}$. Sus límites territoriales están entre las coordenadas $07^{\circ} 10^{\prime}$ sur y $34^{\circ} 50^{\prime}$ oeste (figura 1 ).

Figura 1. Localización del municipio de João Pessoa.

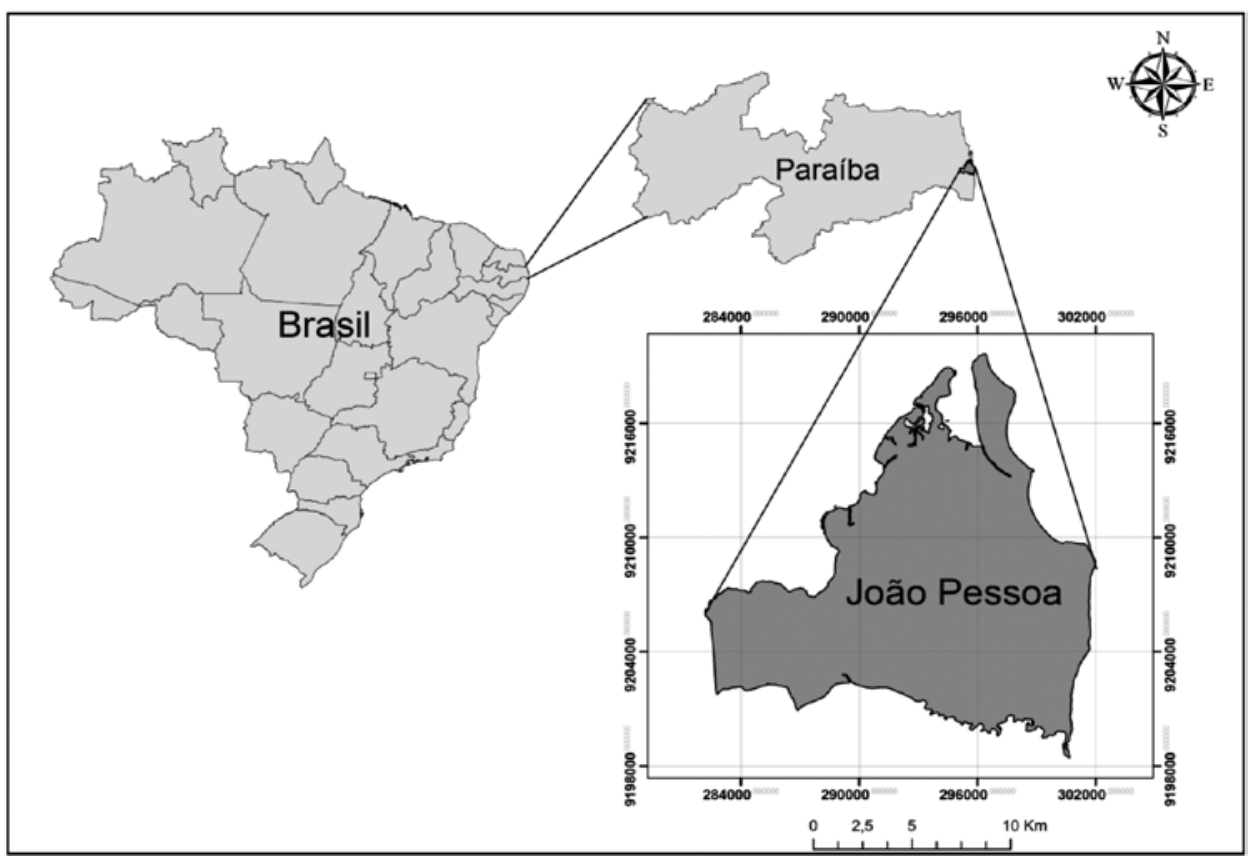

Características Geológicas y Geomorfológicas Generales

El municipio de João Pessoa tiene la mayor parte de su extensión $(67 \%)$ sobre la unidad litoestatigráfica denominada Formación Barreiras - sedimentos arenoarcillosos mal consolidados, que reposan de forma 
discordante respectivamente de oeste a este, sobre el embasamiento cristalino precámbrico y sobre los sedimentos de la Cuenca Sedimentaria Marginal Paraíba (Furrier, Araújo \& Meneses, 2006). La Cuenca Paraíba está llena por sedimentos de facies continentales y marinas, reunidas bajo el nombre de Grupo Paraíba, que a su vez, es subdividido en tres formaciones: la Beberibe, la Gramame y la Maria Farinha (Brasil, 2002). Cubriendo el Grupo Paraíba pero no haciendo parte del mismo, se encuentra la Formación Barreiras del Mioceno.

Los compartimientos geomorfológicos que se presentan en el área de estudio básicamente son: bajas mesetas costeras, tierras bajas litoraneas. Las bajas mesetas costeras son superficies generalmente planas a suavemente onduladas, que acompañan todo el litoral del Noreste de Brasil, con una extensión estimada de 8,42 millones de hectáreas (Brasil, 1994).

Componiendo las tierras bajas litoraneas están las planicies fluviales, marinas, e intermareales, y también las terrazas fluviales y marinas. Las planicies fluviales son las áreas inmediatamente contiguas a los cuerpos de agua, compuestas por sedimentos más finos depositados por los ríos o por la acción del viento. Las planicie intermareales corresponden a las áreas de manglares y las planicies marinas son las áreas de playas que además sufren inundación de las aguas marinas, hasta donde la marea puede avanzar. Las terrazas marinas son antiguas planicies que actualmente no sufren más inundaciones de las mareas y de las olas.

\section{Marco Teórico Conceptual}

Los estudios de las unidades geológicas y geomorfológicas en los sitios urbanos asumen un importante papel con respecto al hecho de planear el uso y ocupación del suelo, por lo tanto, el conocimiento de los aspectos físicos permite que se establezca el mejor aprovechamiento posible del mismo.

La principal base teórico-conceptual para la elaboración del mapeo geomorfológico fue el trabajo de Ross (1992), que tras una descripción minuciosa acerca de este procedimiento, así como este autor afirma que a la hora de diseñar un mapa geomorfológico se deben fortalecer elementos de la descripción del relieve, identificar la naturaleza geomorfológica de todos los elementos del terreno y datar las formas. Por lo tanto son identificados en él, la geología del área, las morfoesculturas, los patrones y tipos de forma del relieve, las pendientes y las formas actuales del relieve. 
Según lo dicho por Guerra y Cunha (2007), la metodología de mapeo geomorfológico tiene como base la ordenación de los fenómenos mapeados, según una taxonomía que debe estar medida a una determinada escala cartográfica. La metodología de Ross (1992) establece que el relieve está dividido en taxones, organizados de forma descrita en el cuadro 1 y en la figura 2.

Cuadro 1. Representación esquemática de las unidades taxonómicas de Ross (1992).

\begin{tabular}{|c|c|}
\hline $\begin{array}{l}1^{\text {er }} \\
\text { Taxón }\end{array}$ & $\begin{array}{l}\text { Unidad morfoestructural - son las estructuras geológicas más amplias, } \\
\text { como las cadenas de montañas, macizos, mestas y depresiones internas de } \\
\text { los continentes y de los océanos. En caso del presente trabajo consiste en la } \\
\text { Cuenca Sedimentaria Paraíba cubierta en partes por la Formación Barreiras } \\
\text { y por sedimentos incosolidados del Cuaternario. }\end{array}$ \\
\hline $2^{\text {do }}$ Taxón & $\begin{array}{l}\text { Unidades morfoesculturales - se relacionan con la acción de los elementos } \\
\text { morfogenéticos sobre las morfoestructuras, son las formas resultantes. Pue- } \\
\text { den ser caracterizados como rasgos del relieve generado sobre las morfoes- } \\
\text { tructuras, a través de procesos exógenos y endógenos. Son morfoesculturas } \\
\text { las mesetas, sierras, planicies entre otros. }\end{array}$ \\
\hline $3^{\text {er }}$ Taxón & $\begin{array}{l}\text { Patrones de formas del relieve - este taxón se refiere a una determinada uni- } \\
\text { dad morfoescultural de dimensión inferior, siendo en este taxón que los pro- } \\
\text { cesos morfoclimáticos actuales comiencen a ser percibidos. Los patrones } \\
\text { de formas del relieve pueden ser: formas de acumulación, como planicies } \\
\text { fluviales y marinas, o formas propias de procesos denudacionales, colinas, } \\
\text { cerros mesetas, entre otros. }\end{array}$ \\
\hline $4^{\text {to }}$ Taxón & $\begin{array}{l}\text { Tipos de forma del relieve - este taxón está fundamentado en la disección } \\
\text { del relieve. El mapeo lleva en consideración las dimensiones interfluviales } \\
\text { y el grado de profundidad del drenaje. En el relieve en meseta prevalece } \\
\text { la pedogénesis, considerando la superioridad de la infiltración sobre el } \\
\text { escurrimiento. El grado de evolución del relieve refleja en conjunto los } \\
\text { componentes tratados (pedogénesis y morfogénesis), que puede ser justi- } \\
\text { ficado por la intensidad de incisión del drenaje, cuya densidad se refleja } \\
\text { en la dimensión interfluvial. }\end{array}$ \\
\hline $5^{\text {to }}$ Taxón & $\begin{array}{l}\text { Sectores de las pendientes - pertenecen a cada una de las formas indivi- } \\
\text { dualizadas del relieve, cuya forma puede ser convexa, rectilínea y cóncava. }\end{array}$ \\
\hline $6^{\text {to }}$ Taxón & $\begin{array}{l}\text { Pequeñas formas del relieve - Aquellas resultantes de procesos actuales; } \\
\text { por ejemplo, cárcavas, hondonadas y bancos de sedimentación, además de } \\
\text { formas producidas por el hombre como cortes, rellanos entre otros. }\end{array}$ \\
\hline
\end{tabular}


Figura 2. Representación esquemática de las unidades taxonómicas

(Modificada de Ross, 1992)

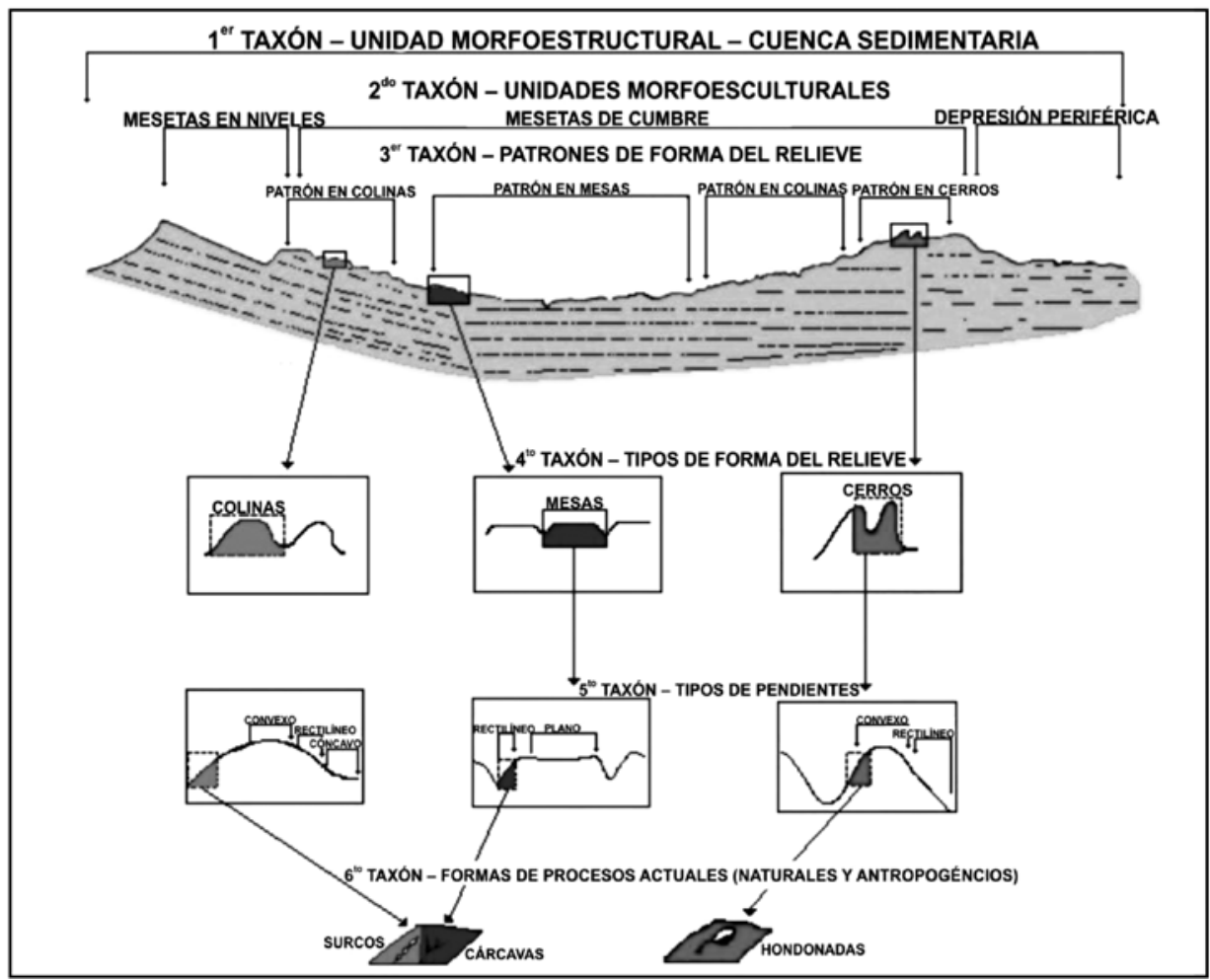

En la distinción del sexto taxón, que son las formas de procesos actuales, cabe destacar que esos procesos pueden tener orígenes diferentes y ser generados por acción natural o por labor antrópica. Cuando estas formas son de origen antrópico, es necesario analizarlas bajo el sesgo de la teoría del relieve tecnogénico o geomorfología antropogénica, tratada en diversos trabajos como los de Peloggia (1998), Szabó (2010) y Csima (2010).

El alcance de la geomorfología antropogénica no incluye apenas el estudio de las formas del relieve creadas por el hombre, sino también la investigacion de las alteraciones de la superficie inducidas por el hombre, el equilibrio de los procesos naturales perturbados, como también la formulación de propuestas con el fin de impedir impactos negativos. En los trabajos escritos en las últimas décadas, han sido identificadas las siguientes áreas de la geomorfología antropogénica: minería; impacto industrial; 
expansión de los asentamientos urbanos; agricultura; y los impactos del turismo y actividades deportivas, que son bastante nuevas y son campos de estudio de la geomorfología antropogénica.

\section{Marco Metodológico}

Los procesos metodológicos propuestos en este trabajo fueron: la realización de una revisión bibliográfica referente a los sesgos de la geología y geomorfología en los aspectos generales y concernientes al área de estudio, también la consulta de materiales cartográficos, fotografías áreas e imágenes de satélite para apoyar a la interpretación del área; la confección de mapas temáticos de hipsometría e inclinación de las pendientes, que ayudara en la elaboración y lectura del mapa geomorfológico; y para finalizar, la elaboración del mapa geomorfológico del municipio que sirve tanto como base para los análisis resultantes en cuanto la síntesis de resultados de la investigación.

\section{Elaboración de los mapas temáticos de hipsometría y de inclina- ción de las pendientes}

Primero fueron reunidas cuatro hojas topográficas de escala 1:25.000, con equidistancia de las curvas de nivel de $10 \mathrm{~m}$, que abarcan toda el área del municipio de João Pessoa: las hojas Santa Rita, João Pessoa, Nossa Senhora de Penha y Mata da Aldeia (Brasil, 1974), estas fueron utilizadas como base cartográfica de toda la investigación. El procedimiento inicial consistió en la digitalización de las hojas citadas, transformando las imágenes en archivos digitales en formato raster.

Para transformar la imagen de formato raster a formato vectorial fue necesario vectorizar las hojas topográficas digitalizadas. En este caso, fue empleado el procedimiento de la vectorización manual realizada en el programa de extensión CAD, y posteriormente, los productos vectoriales fueron importados en ambiente SIG, para la generación de las matrices regular e irregular, MNT, y confección de los mapas de inclinación de las pendientes, conforme a la clasificación delimitada por Herz y De Biase (1989), y de hipsometría. El SIG utilizado para la generación de los mapas fue el software Spring 5.2, que es un SIG producido y disponible de forma gratuita por el Instituto Nacional de Pesquisas Espaciais (INPE), de Brasil.

Para la elaboración del mapa de hipsometría los procedimientos básicos en Spring 5.2 fueron una creación de las clases de altimetría, 
variando de 10 en 10 metros con la atribución de sus debidos colores, y la división de las clases en el menú MNT, generando el mapa hipsométrico, que posteriormente paso por edición matricial para suavizar los errores de atribución de clases según el valor de las muestras.

El proceso de elaboración del mapa de inclinación de las pendientes consistió en generar en principio un TIN y después crear las clases de inclinación de las pendientes, variando de 0 a $>100 \%$, atribuyendo sus debidos colores, generando así el mapa de inclinación de las pendientes. La definición de las clases de inclinación de las pendientes usadas en este trabajo fue basada en Herz y De Biase (1989), que ajustaron esas clases a límites usados internacionalmente y al antiguo Código Florestal de Brasil. Esas clases fueron clasificadas de la siguiente forma:

- $\quad<12 \%$ : el límite máximo de empleo de mecanización en la agricultura;

- $\quad 12-30 \%$ : la ley Federal $n^{\circ} 6766 / 1979$ limita en un 30\% de inclinación de la pendiente la urbanización sin restricciones;

- $\quad 30-47 \%$ : la ley Federal no 4761/1965 (Código Florestal) limita en un $47 \%$ de inclinación de las pendientes la tala de vegetación;

- $\quad 47-100 \%$ : en este intervalo de inclinación de las pendientes el Código Florestal prohíbe la tala de bosques sin un régimen de utilización racional que sea destinado a ingresos permanentes;

- $\quad>100 \%$ : es considerada, por el Código Florestal área de preservación permanente, apenas siendo admitida la eliminación total o parcial de la vegetación, con previa autorización del Poder Público Federal, cuando fuera necesaria la ejecución de actividades o proyectos de utilidad pública o de interés social.

\section{Elaboración del mapa geomorfológico}

Para la elaboración del mapa geomorfológico fue necesaria la sobreposición e interpretación de diversos productos cartográficos y, además de esto, visitas a campo. El mapa geomorfológico producido en esta investigación fue elaborado de acuerdo con la metodología desarrollada por Ross (1992), con ajuste hechos por Furrier (2007) para la adaptación de la escala y el relieve predominantemente en mesetas del área. Para un mejor entendimiento todo el proceso será descrito en 5 fases: 
Fase 1: determinación del $1^{\text {er }}$ taxón, referente a la morfoestructura. En el área de estudio fueron establecidos 3 dominios: sedimentos cuaternarios, cobertura residual de plataforma (sedimentos de la Formación Barreiras) y la Cuenca Sedimentaria Paraíba.

Fase 2: determinación de la morfoescultura que son las grandes formas del relieve que predominan en el área. Para la región comprendida por el municipio de João Pessoa fueron definidas dos: las Tierras Bajas Litoraneas y las Bajas Mesetas Costeras.

Fase 3: determinación de los patrones de forma del relieve. Para la determinación de este taxón fue necesario el uso de una imagen sombreada, imagen de satélite y las hojas topográficas, donde se pudieran ver los patrones de formas del relieve, desde formas de denudación y de acumulación.

Fase 4: determinación de los tipos de formas del relieve. En este trabajo fueron clasificadas un total de seis formas de acumulación (formas de planicie intermareal; formas de planicie fluvial; formas de terrazas y planicies marinas; formas de coluvio y terraza fluvial).

Las formas de denudación en el presente trabajo se dividen en dos tipos: formas en mesetas y convexa. Dentro de esta división existen subdivisiones: se traza una recta en la región central del curso principal de una determinada cuenca, en seguida se observa la diferencia altimétrica entre las dos extremidades de la recta (Tabla 1), en la columna se encuentra la clase de entallamiento medio de los valles que va de muy débil hasta muy fuerte, en seguida se mide la longitud de los divisores de agua donde el curso de agua está instalado, el cual se refiere a la fila de la tabla, que dice respecto a la dimensión interfluvial media, que va desde muy grande a muy pequeña.

En el presente trabajo fueron clasificadas, en general, tres formas denudacionales (meseta 41 , meseta 31 y convexa 41 ).

Fase 5: el quinto taxón consistió en un análisis de las pendientes observadas en campo y en el mapa de inclinación de las pendientes. La descripción de estas pendientes no estará en el mapa geomorfológico debido a su escala, más será incorporada en el texto. El sexto taxón son las características actuales identificadas, en este caso, el material usado fue una imagen de satélite, fotografías aéreas e 
idas a campo, donde las formas fueron verificadas y luego trazadas con el auxilio de un GPS.

Tabla 1. Matriz de los índices de disección de las formas del relieve

\begin{tabular}{|l|c|c|c|c|c|}
\hline \multirow{2}{*}{$\begin{array}{c}\text { Grado de } \\
\begin{array}{c}\text { Entallamiento } \\
\text { de los Valles }\end{array}\end{array}$} & $\begin{array}{c}\text { Muy } \\
\text { Grande (1) } \\
\mathbf{> 1 5 0 0} \mathbf{~ m}\end{array}$ & $\begin{array}{c}\text { Grande (2) } \\
\mathbf{1 5 0 0} \text { a 700 } \mathbf{~ m}\end{array}$ & $\begin{array}{c}\text { Media (3) } \\
\mathbf{7 0 0} \text { a 300 } \mathbf{~ m}\end{array}$ & $\begin{array}{c}\text { Pequeña (4) } \\
\mathbf{3 0 0} \text { a 100 } \mathbf{~ m}\end{array}$ & $\begin{array}{c}\text { Muy } \\
\text { Pequeña (5) } \\
<\mathbf{1 0 0} \mathbf{~ m}\end{array}$ \\
\hline Muy débil (1) $<10 \mathrm{~m}$ & 11 & 12 & 13 & 14 & 15 \\
\hline Débil (2) $10-20 \mathrm{~m}$ & 21 & 22 & 23 & 24 & 25 \\
\hline Medio (3) $20-40 \mathrm{~m}$ & 31 & 32 & 33 & 34 & 35 \\
\hline Fuerte (4) $40-80 \mathrm{~m}$ & 41 & 42 & 43 & 44 & 45 \\
\hline Muy fuerte (5) $>80 \mathrm{~m}$ & 51 & 52 & 53 & 54 & 55 \\
\hline
\end{tabular}

Fuente: Ross (1992)

\section{Resultados}

\section{Hipsometría e inclinación de las pendientes}

La elaboración del mapa de hipsometría del municipio en estudio permitió algunos análisis como la variación topográfica que acaba por sectorizar el municipio donde las planicies costeras, fluviales e intermareales se encuentran en la cota altimétrica de $0-10 \mathrm{~m}$, pudiendo contener cotas de hasta $30 \mathrm{~m}$. Siguiendo en dirección al interior del municipio en el sentido oeste, se tiene cotas de hasta $40 \mathrm{~m}$, y posteriormente, mesetas que van de $40-60 \mathrm{~m}$ en la porción centro oeste, siendo interrumpidas solamente por un valle con cotas de cerca de $30 \mathrm{~m}$ (Figura 3 ).

El valle del arroyo Mussuré tiene la peculiaridad de que fluye en dirección opuesta a la inclinación general del terreno que tiene dirección $\mathrm{O}$ -E. En este segmento alrededor de este arroyo, de acuerdo con el MNT, no son observadas mesetas y si una superficie semicolinosa a convexa. Esta morfología difiere de la mayor parte del municipio que tiene predominio en formas de mesetas en su sector denudacional.

En algunos años, con el progreso de la erosión del nacimiento del rio Jaguaribe y arroyo Mussuré podrá haber una captura de drenaje pudiendo transformar la configuración de la red hidrográfica del municipio de forma consustancial (figura 3). 
Figura 3. Mapa hipsométrico del municipio de João Pessoa

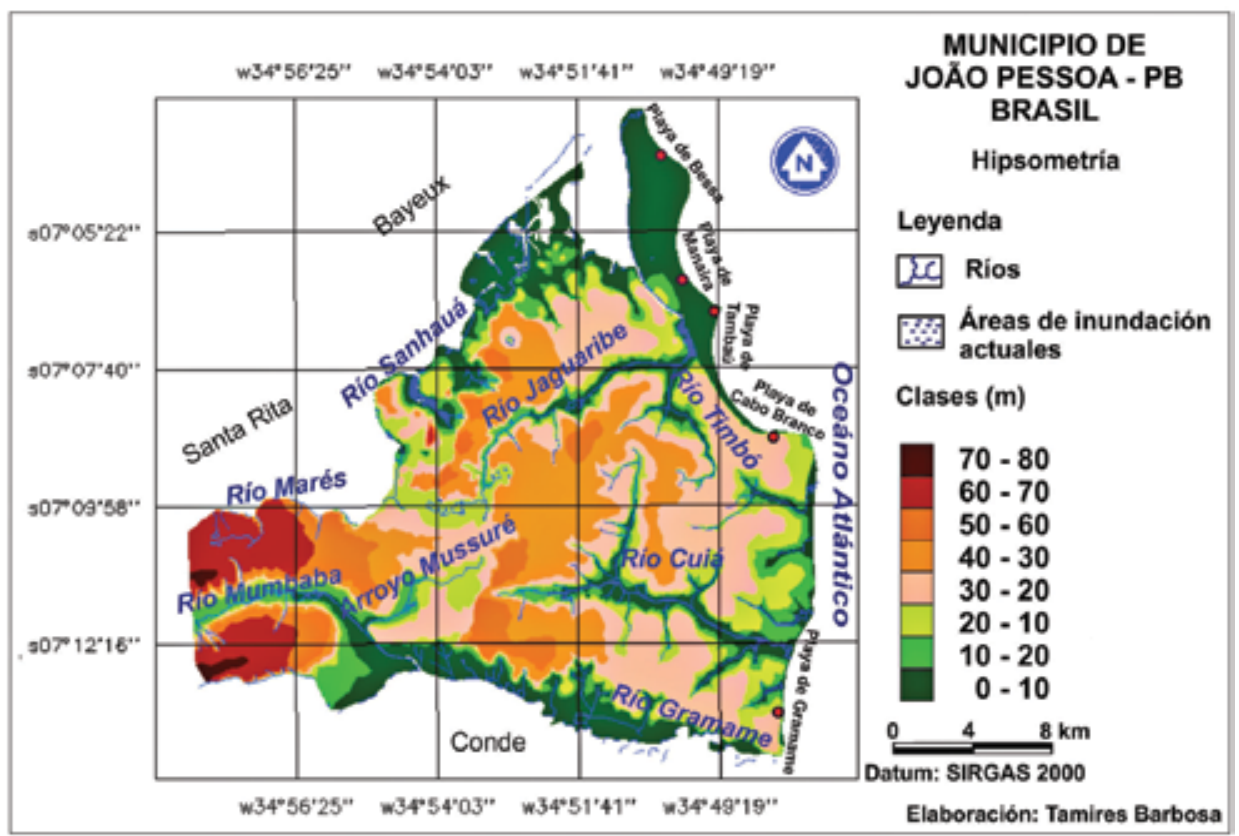

La tabla 2 muestra la proporción en $\mathrm{km}^{2}$ y en porcentaje de cada clase hipsométrica en el municipio de João Pessoa.

Tabla 2. Clases de hipsometría en el municipio de João Pessoa en $\mathrm{km}^{2} \mathrm{y}$ en porcentaje.

\begin{tabular}{|c|c|c|}
\hline Clases (m) & Área (km2) & Área (\%) \\
\hline $0-10$ & 42,71 & 21 \\
\hline $10-20$ & 20,13 & 10 \\
\hline $20-30$ & 29,77 & 15 \\
\hline $30-40$ & 50,97 & 25 \\
\hline $40-50$ & 33,31 & 17 \\
\hline $50-60$ & 13,19 & 7 \\
\hline $60-70$ & 10,55 & 5 \\
\hline $70-80$ & 0,85 & $<1$ \\
\hline
\end{tabular}


El mapa de inclinación de las pendientes muestra la declividad del terreno, que va de $0-12 \%$ a $>100 \%$ donde son verificadas las pendientes con la mayor declividad. Este mapa es una gran herramienta para los estudios de carácter ambiental dado que con la identificación de áreas con mayor pendiente se puede inferir cuales de esas áreas podrán ofrecer mayores riesgos para el medio y/o para el hombre (Figura 4).

Figura 4. Mapa de inclinación de las pendientes del municipio de João Pessoa.

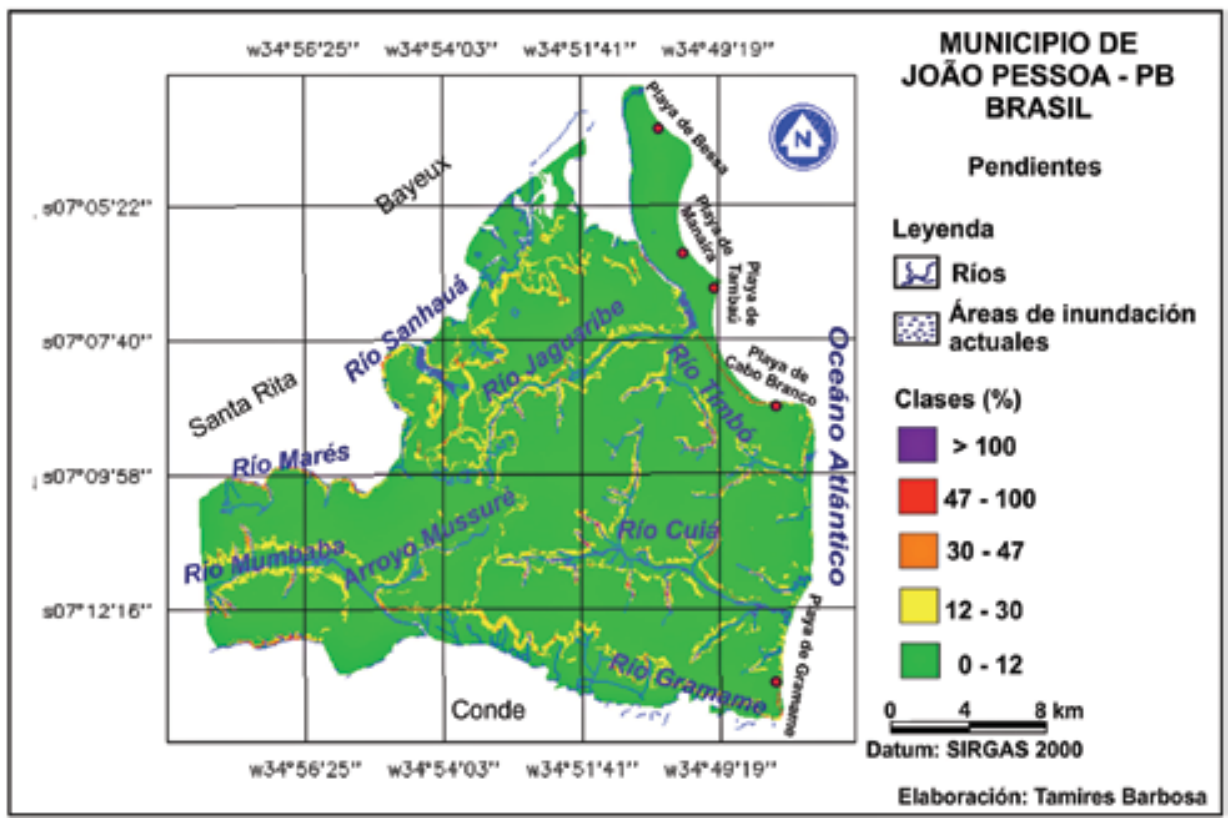

La mayor parte del municipio de João Pessoa posee pendientes que van de $0-12 \%$, eso ocurre por estar un terreno en relieve de mesetas bajas y extensas áreas agradacionales, por lo tanto, intervalos menores de pendientes acentuadas también ocurren, principalmente al lado de los valles más disectados y en los acantilados activos que pueden llegar hasta 100\% de declividad.

La tabla 3 muestra una proporción en $\mathrm{km}^{2}$ y porcentaje de cada clase de pendiente en el municipio de João Pessoa. 
Tabla 3. Clases de inclinación de las pendientes en el municipio de João Pessoa en $\mathrm{km}^{2} \mathrm{y}$ en porcentaje.

\begin{tabular}{|c|c|c|}
\hline Clases (\%) & Área $\mathbf{( k m}^{\mathbf{2}} \mathbf{~}$ & Área (\%) \\
\hline $0-12$ & 184,45 & 92 \\
\hline $12-30$ & 14,1 & 7 \\
\hline $30-47$ & 2,15 & 1 \\
\hline $47-100$ & 0,72 & $<1$ \\
\hline$>100$ & 0,02 & $<1$ \\
\hline
\end{tabular}

\section{Geología}

La región donde está ubicada el municipio de João Pessoa se encuentra integralmente dentro de Cuenca Sedimentaria Paraíba (Barbosa et al., 2003). Mabesoone y Alheiros (1991) describe la Cuenca Paraíba como una estructura en forma de homoclinal con inclinación suave en dirección al oceáno, el cual es subdividido por las fallas transversales. El nacho medio de la franja sedimentaria es de aproximadamente $25 \mathrm{~km}$ y su espesor máximo puede llegar a $400 \mathrm{~m}$ de profundidad. El área de estudio esa totalmente localizada en la sub cuenca Alhandra.

Según Petri y Fúlfaro (1988), la secuencia sedimentaria más antigua de la franja costera de la Cuenca Paraíba pertenece al intervalo Campaniano o Turoniano-Paleoceno, en contacto con el embasamiento cristalino precámbrico. Está compuesta desde el sustrato hasta la superficie, por las formaciones Beberibe, Gramame y Maria Farinha (Grupo Paraíba), siendo la primera de composición clástica y las dos últimas formadas por calizas, y que prueba que esta área viene sufriendo influencias tectónicas desde a abertura del Atlántico. Con el movimiento de América del Sur para el oeste, esta tectónica sigue activa.

Sobre la Cuenca Paraíba, se encuentra la Formación Barreiras formada por sedimento arenoarcillosos mal consolidados del Mioceno. A pesar de que el municipio João Pessoa presenta la Formación Barreiras como unidad geológica de mayor extensión (Figura 5 y Tabla 4), presenta también extensas áreas de sedimentos cuaternarios inconsolidados y se puede destacar que las demás unidades del Grupo Paraíba también afloran en fragmentos de menor extensión en el municipio. 
Figura 5. Mapa geológico de João Pessoa

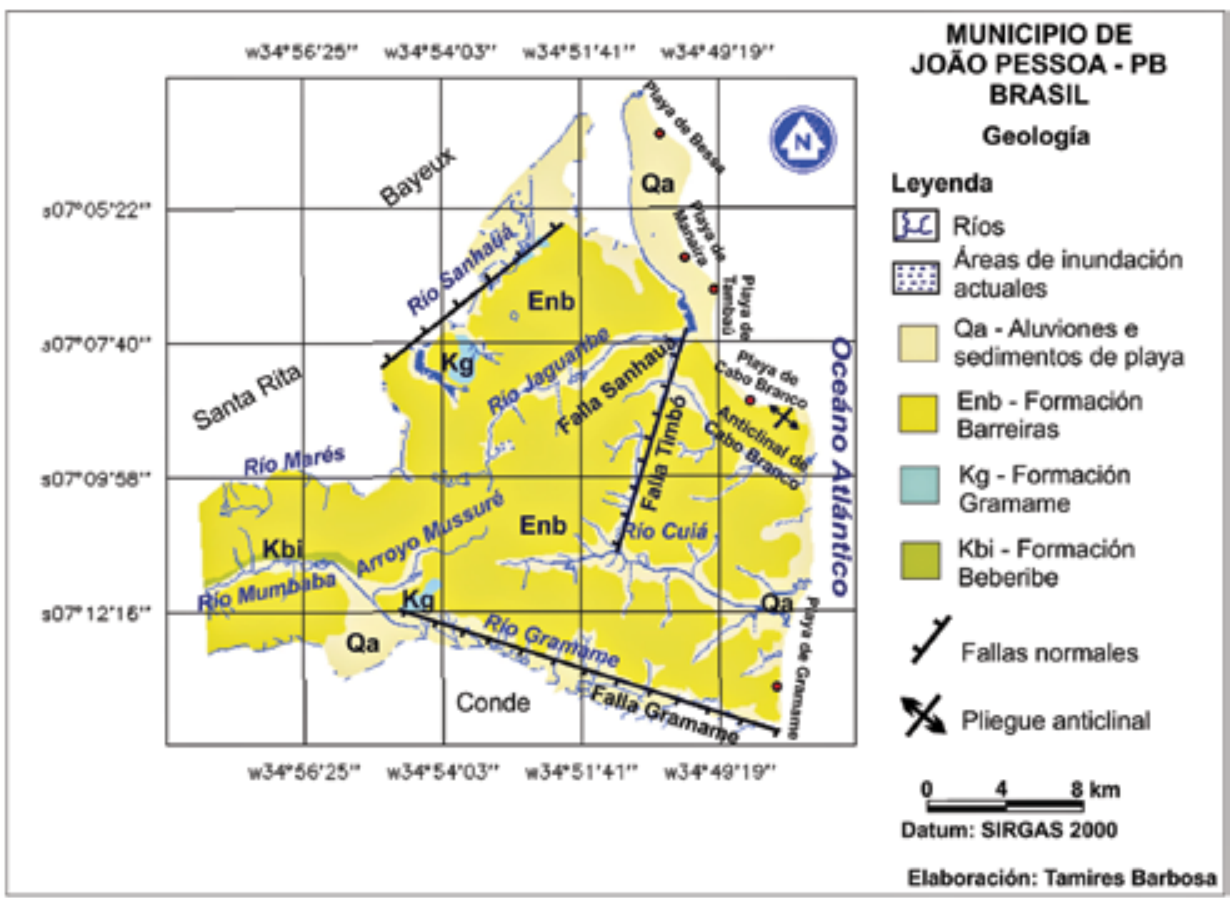

Fuente: Modificado de Brasil (2002).

Araújo (2012) señala afloramientos de la Formación Gramame en las proximidades de los valles de los ríos Gramame y Sanhauá, donde existe actividad de minería con extracción de calizas en las minas de la fábrica de cemento CIMPOR y en áreas de minería clandestina, como las canteras de Roger y Mandacaru. Hay también un afloramiento de la Formación Beberibe en el valle del río Mumbaba.

Tabla 4. Formaciones geológicas en el municipio de João Pessoa en $\mathrm{km}^{2}$ y en porcentaje.

\begin{tabular}{|c|c|c|}
\hline Clases & Área $\left.\mathbf{( k m}^{\mathbf{2}}\right)$ & Área $\mathbf{( \% )}$ \\
\hline Aluviones y sedimentos de playa & 64,861 & 32 \\
\hline Formación Barreiras & 136,570 & 67 \\
\hline Formación Gramame & 1,899 & 0,9 \\
\hline Formación Beberibe & 1,223 & 0,1 \\
\hline
\end{tabular}




\section{Mapa geomorfológico}

Analizando el mapa geomorfológico elaborado (figura 6), se puede explicar que el primer taxón abarca las unidades geológicas presentes en el municipio - los sedimentos cuaternarios y la cobertura sedimentaria de plataforma, compuesta por la Formación Barreiras. Estas unidades geológicas se encuentran sobre la Cuenca Sedimentaria Paraíba que también se coloca como morfoestructura en el área correspondiente en el municipio de João Pessoa.

El segundo taxón es compuesto por unidades morfoesculturales que comprende, en el área de estudio, las tierras bajas litoraneas y las bajas mesetas costeras. El tercero y cuarto taxón corresponden respectivamente a los patrones y a los tipos de formas del relieve. Para un mejor entendimiento estos serán analizados conjuntamente.

Se pueden observar tres formas de denudación: las formas denudacionales en mesetas Dm 41 y Dm 31; y la dedunacional convexa Dc 41 explicadas a continuación.

Dm 41: son formas de disectación en mesetas con entallamiento medio del valle de intensidad fuerte $(40-80 \mathrm{~m})$, y con dimensión interfuvial media clasificada como muy grande $(>1500 \mathrm{~m})$. Este tipo de forma está localizado en la región próxima del río Mumbaba y en la margen izquierda del río Jaguaribe (figura 6). Este patrón de relieve ocupa $73 \mathrm{~km}^{2}$ y $35 \%$ del área del municipio;

Dm 31: formas de disectación en mesetas con entallamiento medio del valle clasificado como de tipo de medio $(20-40 \mathrm{~m})$, y dimensión interfluvial media muy grande $(>1500 \mathrm{~m})$. La localización de estas formas en el municipio se encuentra en áreas próximas a la cuenca del río Cuiá, en ambas márgenes ocupando $78 \mathrm{Km}^{2}$ y $38 \%$ del área del municipio;

Dc 41: además de la formas en mesetas se encuentra en el municipio de João Pessoa un fragmento cuya disposición de relieve forma superficies en ápices convexos. Esta área está localizada en las proximidades del arroyo Mussuré, afluente del río Mumbaba. Este arroyo es clasificado como obsecuente, por correr en dirección contraria a la inclinación del terreno, y tal anomalía puede ser causada por levantamiento tectónico en la parte suroeste del municipio de João Pessoa donde se encuentran las mayores cotas de altimétricas (ver mapa hipsométrico, figura 4). Este tipo de forma ocupa $12,7 \mathrm{Km}^{2}$ y $6 \%$ del área del municipio (figura 6); 
En relación a las formas de acumulación, fueron incorporados nuevos términos por Furrier (2007) que son aglutinaciones de los términos propuestos por Ross (1992) y la incorporación de formas de acumulación coluviales. Estas aglutinaciones se hicieron necesarias debido a la escala adoptada, pues en algunos casos no fue posible separar, por ejemplo, terraza fluvial de planicie fluvial, terraza marina de planicie marina, depósito de coluvio de terraza fluvial. En total fueron identificados 6 tipos de formas de acumulación en el municipio: áreas de planicies intermareal y fluvial; planicies y terrazas marinas, planicies y terrazas fluviales; coluvio, planicie y terraza fluvial; y coluvio y terraza fluvial (figura 6).

Figura 6. Mapa geomorfológico del munícipio de João Pessoa.

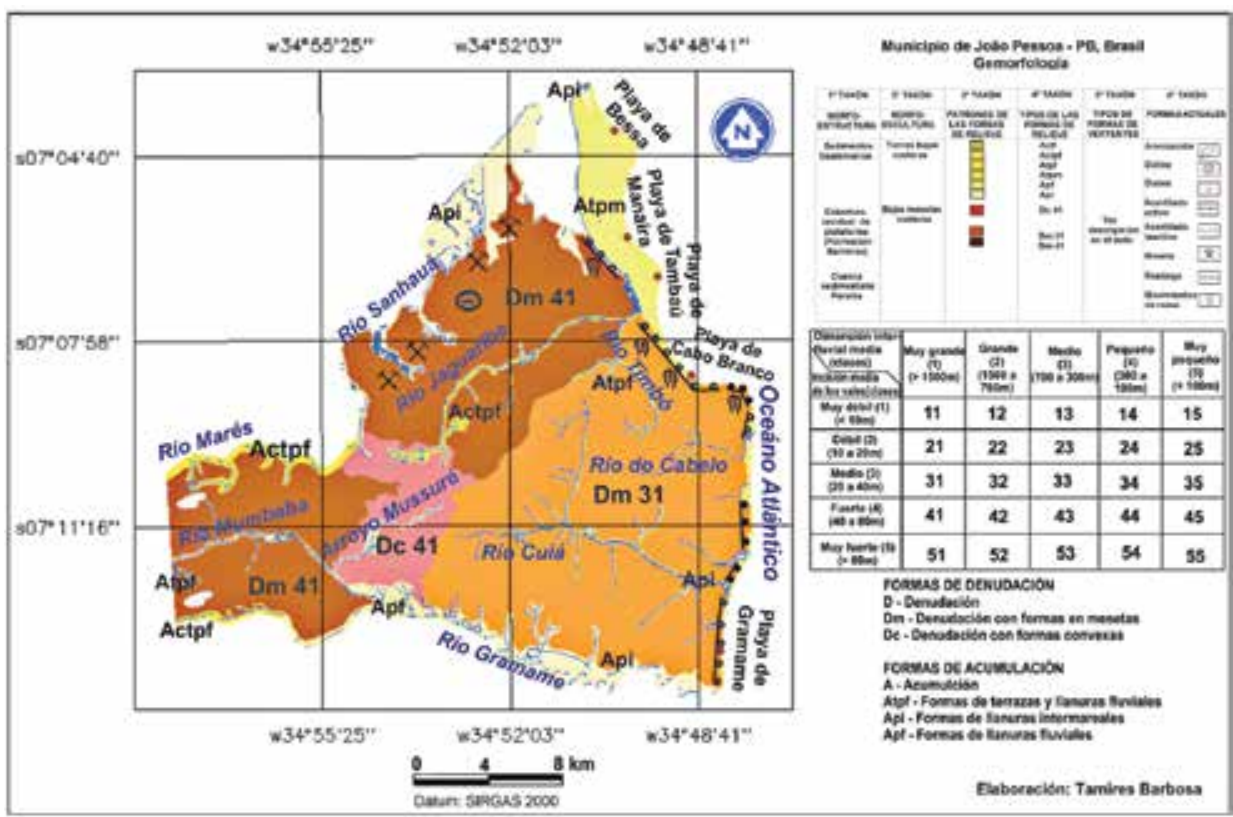

Área de planicie intermareal (Api): la planicie intermareal corresponde a las áreas de manglar. En el municipio ella ocupa un área de $17,5 \mathrm{~km}^{2}$ y $8 \%$ del área total del municipio y ocurre principalmente en las margen del río Sanhauá y en aguas abajo de los ríos Gramame, Cuiá, Aratu y Cabelo (Figura 6).

Área de planicie fluvial (Apf) : son aquellas yuxtapuestas al canal fluvial (Guerra \& Guerra, 1997) ocupan $6,3 \mathrm{~km}^{2}$ y $3 \%$ del área de estudio, 
localizada en segmentos del rio Gramame, arroyo Mussuré, río Cuiá, Aratu y Cabelo (Figura 6).

Área de terraza y planicie marina (Atpm): se encuentran en las áreas de playa y su parte trasera, ocupando $10,6 \mathrm{~km}^{2}$ y $6 \%$ del municipio. Las planicies marinas son las áreas de playa que aún sufren inundación por las aguas marinas, hasta donde la marea puede avanzar. Las terrazas marinas son antiguas planicies marinas que actualmente no sufren más inundación debido al retroceso del mar que alcanzo su última ápice en el litoral brasilero a 5600 AP (Suguio \& Martin, 1978). Su área de mayor cobertura geográfica se encuentra al noreste del área de estudio, donde se encuentran los barrios de Tambaú, Manaíra y Bessa (Figura 6).

Área de Terraza y Planicie Fluvial (Atpf): la terraza fluvial es constituida por material aluvionar más antiguo y en el nivel más alto que el actual de la planicie aluvionar y que fue testimonio de un periodo de la evolución de esta planicie. Planicie fluvial es la franja del valle fluvial compuesta de sedimentos aluviales actuales, bordeando el curso de agua y periódicamente inundado por las aguas de desbordamiento provenientes del rio. Ocurren en João Pessoa en afluentes del río Mumbaba, segmentos del río Jaguaribe, río Timbó y el río Cuiá, constituyen un área de $3,6 \mathrm{Km}^{2}$ y 1\% del municipio (Figura 6).

Área de coluvio, terraza y planicie fluvial (Actpf): debido a la escala adoptada en este trabajo, no fue posible diferenciar los coluvios de las terrazas en ciertos puntos, por eso la adaptación metodológica de Furrier (2007) fue utilizada. Los coluvios son porciones tierras formadas por el material transportado de una ubicación a otra, principalmente por la gravedad. El material coluvial solo aparece al pie de una pendiente (Guerra \& Guerra, 1997). Este tipo de forma ocupa $7,8 \mathrm{~km}^{2}$ y $3 \%$ del área.

Área de coluvio y terraza fluvial (Actf): ocupa $0,1 \mathrm{~km}^{2}$ en el municipio, esta área consiste en la presencia de los coluvios y terrazas, donde no aparece la planicie. Se dan en ríos encajados y con pendientes con elevada inclinación. En João Pessoa este tipo de forma aparece en un afluente del río Mumbaba (Figura 6).

El quinto taxón se refiere a los sectores de las pendientes, y será descrito en una sección específica en este artículo. El sexto taxón corresponde a las formas del relieve, resultante de procesos actuales. En el área de estudio se puede encontrar como principales formas actuales los acantilados, las formas resultantes de movimientos de masa, y las formas producidas 
por el hombre en las minas de extracción de caliza que se encuentran en el sector noroeste del municipio.

Los acantilados no acompañan todo el litoral del municipio, siendo los barrios costeros del sector norte construidos sobre planicies y terrazas marinas. Siguiendo en dirección al sur aparecen los acantilados inactivos y posteriormente una rotación entre acantilados activos e inactivos hasta el extremo sur del municipio.

Algunos de estos acantilados, siendo activos e inactivos, exponen indicios de riesgos geológico-geomorfológicos debido a la inclinación de las pendientes y la acción del mar en el caso de los activos, que según el mapa de inclinación de las pendientes presenta inclinaciones de $47-100 \%$ (ver figura 5). Fueron encontrados puntos donde ocurre, actualmente, intensa erosión por el choque de olas en las mareas altas y consecuentemente retroceso erosivo acelerado del acantilado. Esta erosión acelerada es más crítica en el sur de la playa de Cabo Branco (figura 7), siendo este sector un área de inestabilidad y riesgo geológico permanente.

Figura 7. Acantilados activos con elevada declividad en la playa de Cabo Branco.

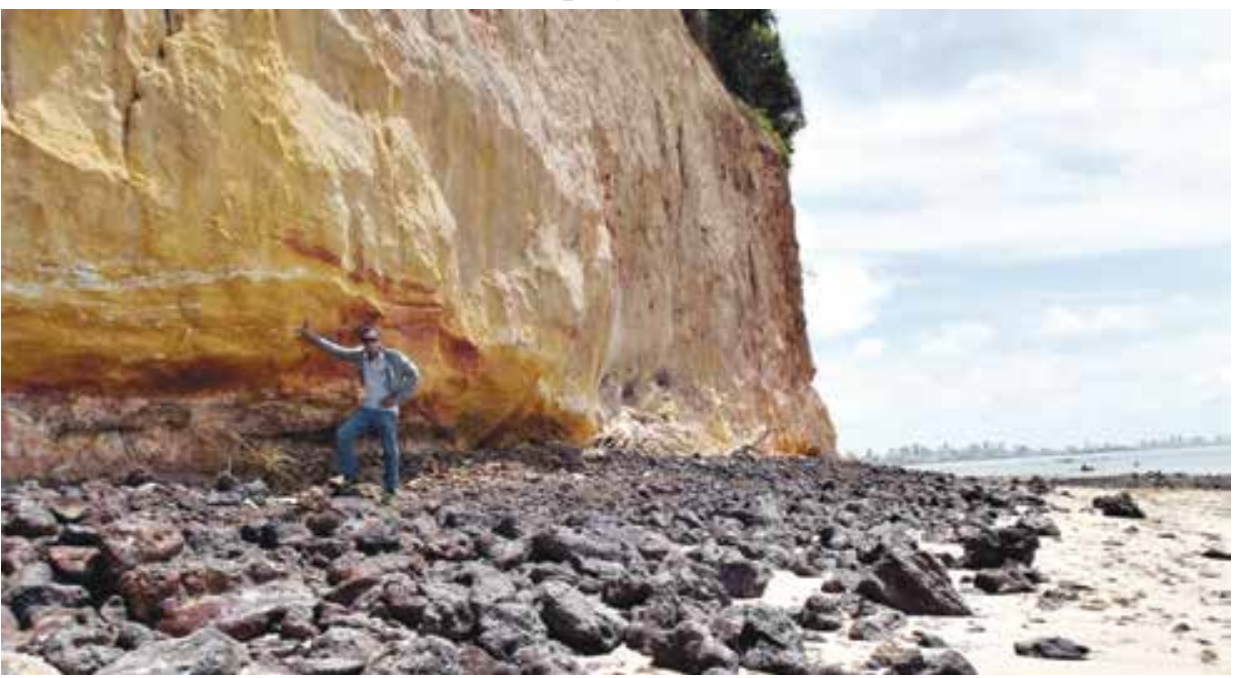

Cabe resaltar que los puntos que generan riesgos de movimientos de masa presentes en el municipio provienen de procesos diferenciados. La 
erosión de las pendientes es un proceso natural que puede ser intensificado por acciones antrópicas, ocurriendo con mayor intensidad en áreas donde se presentan construcciones y los cortes de las carreteras en las partes bajas de las pendientes.

La erosión y la consecuente caída de bloques que ocurre en el rango donde los acantilados son activos y reciben la energía de las olas es un proceso donde la acción antrópica poco interfiere, a no ser por la colaboración del peso ejercido sobre los sedimentos de elementos urbanos construidos sobre ellos.

En el litoral sur del municipio, en los barrios de Costa do Sol y Barra de Gramame, las playas, además de fragmentos de acantilados activos, presentan acantilados inactivos con surcos y cono de deyección.

Figura 8. Acantilados inactivos con surcos y conos de deyección en la playa de Barra de Gramame.

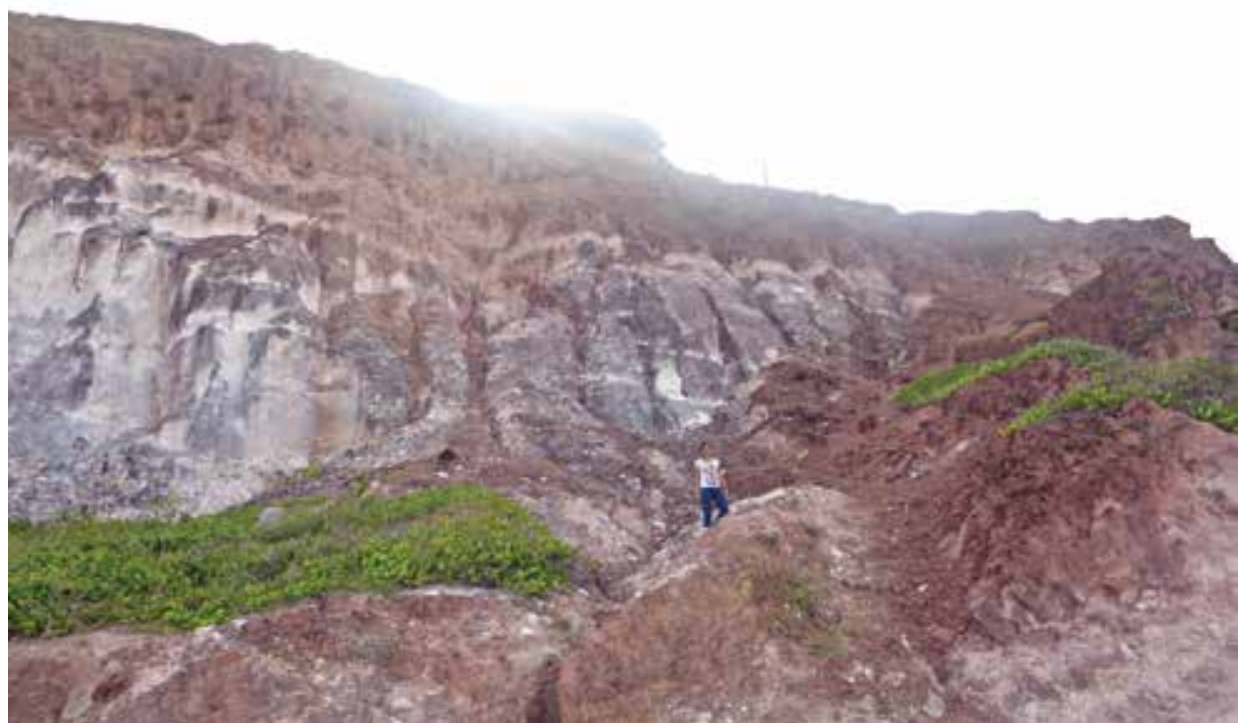

En resumen, la geomorfología del municipio de João Pessoa se puede dividir en dos grandes grupos de formas: las Bajas Mesetas Costeras y las Tierras Bajas Litoraneas. Las mesetas cubren la mayor parte del municipio (79\% del área). Las planicies, terrazas y rampas de coluvios componen las regiones adyacentes a los ríos, playas y su retaguardia, y representa $21 \%$ del área de estudio. 


\section{$5^{\text {to }}$ Taxón - Descripción de las pendientes}

La descripción de las pendientes corresponde al $5^{\text {to }}$ taxón del mapeo geomorfológico de Ross (1992), que equivale a la dimensión de las formas, tamaño medio de los interfluvios y grado de entallamiento de los canales. La aplicación del índice de disección permitirá representar estas informaciones, cuantitativamente, en el propio mapa geomorfológico.

En el análisis de las pendientes observadas en campo y en los mapas temáticos, se observan los patrones de comportamiento del relieve del municipio de João Pessoa, que obedecen el patrón más general, de las mesetas bajas costeras. El municipio está compuesto, básicamente, por superficies en mesetas cortadas por canales fluviales con fuerte incisión que generan, principalmente, pendientes rectilíneas.

Se presentan en el área también pendientes convexas y convexo-rectilíneas. Como por ejemplo la pendiente del rio Sanhauá que se dispone de forma rectilínea y la pendiente del rio Jaguaribe, siendo esta convexo-rectilínea. El área del municipio que no forma mesetas por cuenta de la disposición de la red hidrológica, siendo así, una superficie semicolinosa o convexa, está localizada en la región del arroyo Mussuré, que no obedece a la orientación de otros ríos, desembocando en el rio Mumbaba. Es en esta área que se observa la presencia de pequeñas colinas con pendientes convexas.

\section{Discusión de Resultados}

Esta investigación permitió la construcción de un diagnóstico de bases geológico-geomorfológicas del municipio de João Pessoa, Estado de Paraíba, a través de la metodología de mapeo geomorfológico basada en Ross (1992), con adaptaciones de Furrier (2007). El municipio de João Pessoa, estando en mayor parte de su extensión, sobre mesetas bajas (73\% del área), presenta hoy una fuerte expansión urbana para las demás unidades geomorfológicas presentes, como por ejemplo, la planicie costera, las pendientes con inclinación acentuada y fondo de los valles de los ríos.

Mediante esta perspectiva se observa la necesidad de ampliación de este estudio en una escala de mayor detalle, para que haya la construcción del puente de los datos físicos que fueron obtenidos aquí y los datos socio-económicos que necesitan ser aplicados y relacionados, para que se pueda alcanzar datos seguros, confiables y cuantitativos para una planificación ambiental y ordenamiento territorial del municipio más próximo a la realidad. No es posible cualquier tipo 
de planificación ambiental o de ordenamiento territorial sin un profundo conocimiento del relieve, tanto en sus bases estructurales como esculturales, por lo mismo ser el escenario de las más diversas actividades económicas y sociales.

\section{Agradecimentos}

Os autores deste artigo agradecem ao Conselho Nacional de Desenvolvimento Científico e Tecnológico-CNPq pelo financiamento desta pesquisa através do processo Universal 470200/2013-8.

\section{Referencias}

Araújo, M. (2012). Água e rocha na definição do sítio de Nossa Senhora das Neves, atual cidade João Pessoa - Paraíba. Tese (doutorado em Arquitetura e Urbanismo) - Faculdade de Arquitetura da Universidade Federal da Bahia. Salvador. p.297.

Barbosa, J., Souza, E., Lima Filho, M. \& Neumann, V. (2003). A estratigrafia da Bacia Paraíba: uma reconsideração. Estudos Geológicos. Recife, 13(1), 89-108.

Brasil. (2010). Instituto Brasileiro de Geografia e Estatística. IBGE. Censo demográfico. Obtido em 27 de setembro de 2014. http://cidades. ibge.gov.br/xtras/temas.php?lang=\&-

Brasil. (2002). Ministério de Minas e Energia. CPRM. Geologia e recursos minerais do estado da Paraíba. Mapa geológico do estado da Paraíba. Recife: CPRM, mapa, color. Escala 1: 500.000.

Brasil. (1994). Empresa Brasileira de Pesquisa Agropecuária. EMBRAPA. Plano Diretor do Centro de Pesquisa Agropecuária dos Tabuleiros Costeiros (CPATC). Brasília: Embrapa, SPI. p.40.

Brasil. (1974). Ministério do Interior. Superintendência de Desenvolvimento do Nordeste. Folhas Nossa Senhora da Penha, Santa Rita, João Pessoa e Mata da Aldeia. Recife: SUDENE. Escala 1:25.000.

Csima, P. (2010). Urban Development and Anthropogenic Geomorphology. In: Szabó, J., Dávid, L., Lóczy, D. (Eds.). Anthropogenic geomorphology: a guide to man-made landforms. SPRINGER Science + Business Media B. V., Dordrecht-Heidelberg London-New York, p.179-187.

Furrier, M. (2007). Caracterização geomorfológica e do meio físico da folha João Pessoa 1:100.000. Tese (Doutorado) - Faculdade de Filosofia, Letras e Ciências Humanas. São Paulo: USP. p.213. 
Furrier, M., Araújo, M. \& Meneses, L. (2006). Geomorfologia e tectônica da formação Barreiras no estado da Paraíba. Geologia USP Série Científica. São Paulo, 6(2), 61-70.

Guerra, A. \& Cunha, S. (2007). Geomorfologia: uma atualização de bases e conceitos. Rio de Janeiro: Bertrand Brasil, p.471.

Guerra, A.; Guerra, A. (1997). Novo dicionário geológico-geomorfológico. - Rio de Janeiro: Bertrand Brasil. p.648.

Herz, R.; De Biasi, M. (1989). Critérios e legendas para macrozoneamento costeiro. Ministério da Marinha/Comissão Interministerial para os Recursos do Mar. Brasília. p.198.

Mabesoone, J. \& Alheiros, M. (1991). Base estrutural - faixa sedimentar costeira de Pernambuco, Paraíba e parte do Rio Grande do Norte. Estudos Geológicos. Recife, UFPE/DGEO,10, p.33-43.

Peloggia, A. (1998). O homem e o ambiente geológico: geologia, sociedade e ocupação urbana no município de São Paulo. São Paulo: Xamã, p.270.

Petri, S. \& Fúlfaro, V. (1988). Geologia do Brasil. São Paulo: T. A. Queiroz/EDUSPP. p.631

Ross, J. (2012). Geomorfologia ambiente e planejamento. (9.ed.) São Paulo: Contexto, p.85.

Ross, J. (1996). Geomorfologia aplicada aos EIAs-RIMAs. In: Guerra, A. J. T. \& Cunha, S. B. Geomorfologia e meio ambiente. Rio de Janeiro: Bertrand Brasil, p.394.

Ross, J. (1992). O registro cartográfico dos fatos geomórficos e a questão da taxonomia do relevo, Revista do Departamento de Geografia (USP). São Paulo, 6, 17-29.

Suguio, K. \& Martin, L. (1978). Quaternary marine formations of the State of São Paulo and southern Rio de Janeiro. In: International Symposium on Coastal Evolution in the Quaternary, 1. Special Publication,1.p.55.

Szabó, J. (2010). Anthropogenic Geomorphology: Subject and System. In: Szabó, J., Dávid, L. \& Lóczy, D. (Eds.). Anthropogenic geomorphology: a guide to man-made landforms. SPRINGER Science + Business Media B. V., Dordrecht-Heidelberg London-New York. p.298.

Tricart, J. (1965). Principes et méthodes de la geomorphologie. Paris: Masson. p.496. 